Boise State University

ScholarWorks

Geosciences Faculty Publications and

Presentations

Department of Geosciences

$9-2006$

Crosshole Radar Tomography in a Fluvial Aquifer Near Boise, Idaho

William P. Clement

Boise State University

Warren Barrash

Boise State University

This document was originally published by Society of Exploration Geophysicists in Journal of Environmental and Engineering Geophysics. Copyright restrictions may apply. DOI: 10.2113/JEEG11.3.171 


\title{
Crosshole Radar Tomography in a Fluvial Aquifer near Boise, Idaho
}

\author{
William P. Clement and Warren Barrash \\ Center for Geophysical Investigation of the Shallow Subsurface, Boise State University, Boise, Ida. 83725
}

\begin{abstract}
To determine the distribution of heterogeneities in the saturated zone of an unconfined aquifer in Boise, ID, we compute tomograms for three adjacent well pairs. The fluvial deposits consist of unconsolidated cobbles and sands. We used a curved-ray, finite-difference approximation to the eikonal equation to generate the forward model. The inversion uses a linearized, iterative scheme to determine the slowness distribution from the first arrival traveltimes. The tomograms consist of a layered zone representing the saturated aquifer. The velocities in this saturated zone range between 0.06 to $0.10 \mathrm{~m} / \mathrm{ns}$. We use a variety of methods to assess the reliability of our velocity models. Finally, we compare our results to neutron-derived porosity logs in the wells used for the tomograms. The comparison shows that the trends in porosity derived from the tomograms match the trends in porosity measured with the neutron probe.
\end{abstract}

\section{Introduction}

Ground penetrating radar (GPR) is often used to map stratigraphy in shallow aquifers (Beres and Haeni, 1991; Beres et al., 1999; Huggenberger, 1993; Tronicke et al., 2002). More recently, crosshole radar tomography is being used to characterize the spatial distribution of EM and hydrologic properties in the subsurface. Binley et al. (2001) used crosshole radar to understand fluid flow and the soil moisture content distribution in the vadose zone above a sandstone aquifer. They inverted their data using a straight-ray approximation to the wavefield to determine velocities between wells. Another study, by Chen et al. (2001), used straight-ray tomography to determine the velocity and attenuation structure at the South Oyster site, an unconsolidated aquifer in Virginia. The South Oyster site consists of well-sorted, fine-to-medium grained unconsolidated sands and pebbly sands. Alumbaugh et al. (2002) used curved-ray crosshole radar tomography to study the vadose zone of an unconsolidated and heterogeneous interbedded sand, gravel, and clay fluvial system. To check the validity of their model, they compared the soil moisture distribution derived from their velocity tomograms to neutron-derived soil moisture estimates.

In this work, we use curved-ray tomography to determine the 2-D electromagnetic (EM) velocity distribution in an unconfined, fluvial aquifer. The approach of Alumbaugh et al. (2002) is similar to the approach we use; however, this study focuses on the saturated zone. The EM velocity is sensitive to the amount of water in the system. Thus, in the saturated zone, GPR can be used to determine the porosity distribution. By comparing our results to neutronderived porosity estimates from the wells used in the tomography experiment, we can use this sensitivity to porosity to validate the tomography model. Crosshole tomography provides an image of the porosity distribution in the subsurface.

To determine the velocity distribution, we first establish that the tomograms are consistent with each other by inverting three well pairs that form a crosssection of the aquifer and comparing the results along the common wells. An important aspect of this study is appraising the solution. We look at the data residual distribution and approximations to the diagonal elements of the resolution and covariance matrices. Because water strongly controls the EM velocity, we can relate the EM velocity to the porosity distribution in the saturated zone. We show the strong correlation between water saturated porosity and the EM velocity, finally displaying the radar-derived porosity section.

\section{Hydrogeologic Setting}

The Boise Hydrogeophysical Research Site (BHRS) is a wellfield designed to support hydrologic and geophysical research. The BHRS is located on a gravel bar adjacent to the Boise River (Fig. 1). The aquifer at the BHRS is shallow and unconfined. In 1997 to 1998,18 wells were cored through 18 to $21 \mathrm{~m}$ of unconsolidated, cobble and sand, fluvial deposits and completed into the underlying red clay. The wells and the wellfield were designed to permit a wide range of hydrologic and geophysical testing and to capture shortrange geostatistical information (Barrash and Clemo, 
Journal of Environmental and Engineering Geophysics

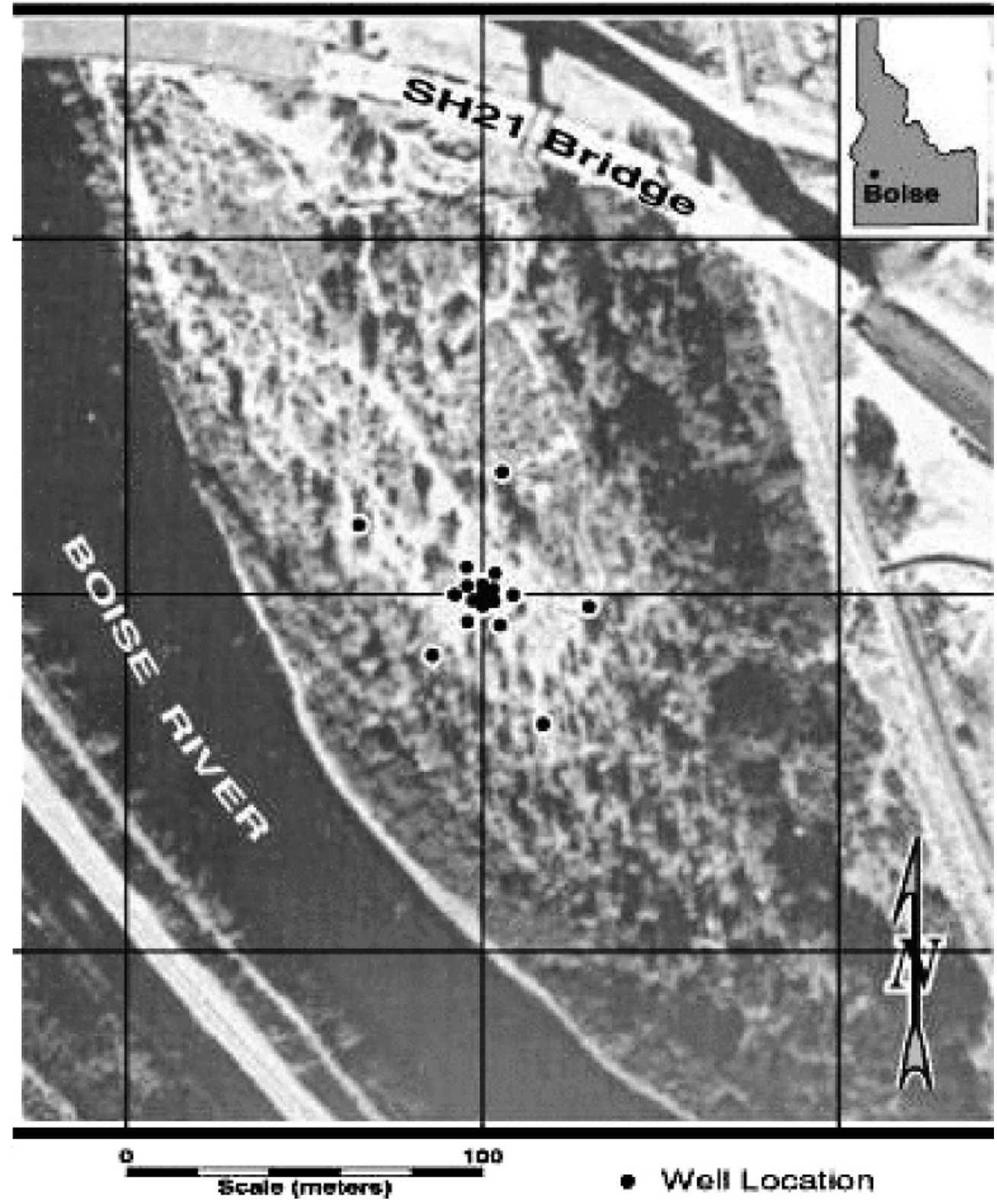

Figure 1. Location map of the BHRS and the well configuration.

2002). In the central area of the BHRS (Fig. 2), 13 wells are arranged in two concentric rings around a central well. Data from porosity logs and core (Barrash and Clemo, 2002; Barrash and Reboulet, 2004) indicate that the coarse fluvial deposits are $\sim 18 \mathrm{~m}$ thick and may be subdivided into five stratigraphic units (Fig. 3). Strong reflections in surface (Clement et al., 1999) and borehole radar (Clement et al., 2001), and borehole seismic (Liberty et al., 2000) profiles occur at some unit boundaries and locally within some units.

Stratigraphy for this site is based on the porosity character from neutron probes and supported by grain size analysis (Fig. 3). A sand-filled channel (Unit 5) occurs at the top of the saturated section. The channel thickens toward the Boise River to the southwest and pinches out between wells B4 and B2 at the center of the wellfield (Fig. 3). Units 1 and 3 consist of low-porosity (average porosity $0.17-0.18$ ), cobble-dominated units with no relatively sand-rich lenses. Cobble-size framework grains dominate Units 2 and 4 also, but these units have higher (average porosity $0.23-0.24$ ) and more variable porosity and some sand-rich lenses. In particular, strong porosity contrasts occur within Unit 4 at the boundaries of local lenses (e.g., at 4.5 and $5.5 \mathrm{~m}$ in well C5 and at 5.5 and $7 \mathrm{~m}$ in well B3; see Fig. 3) with varying proportions of framework cobbles and matrix sand (Barrash and Clemo, 2002; Barrash and Reboulet, 2004). 
Clement and Barrash: Crosshole Radar Tomography

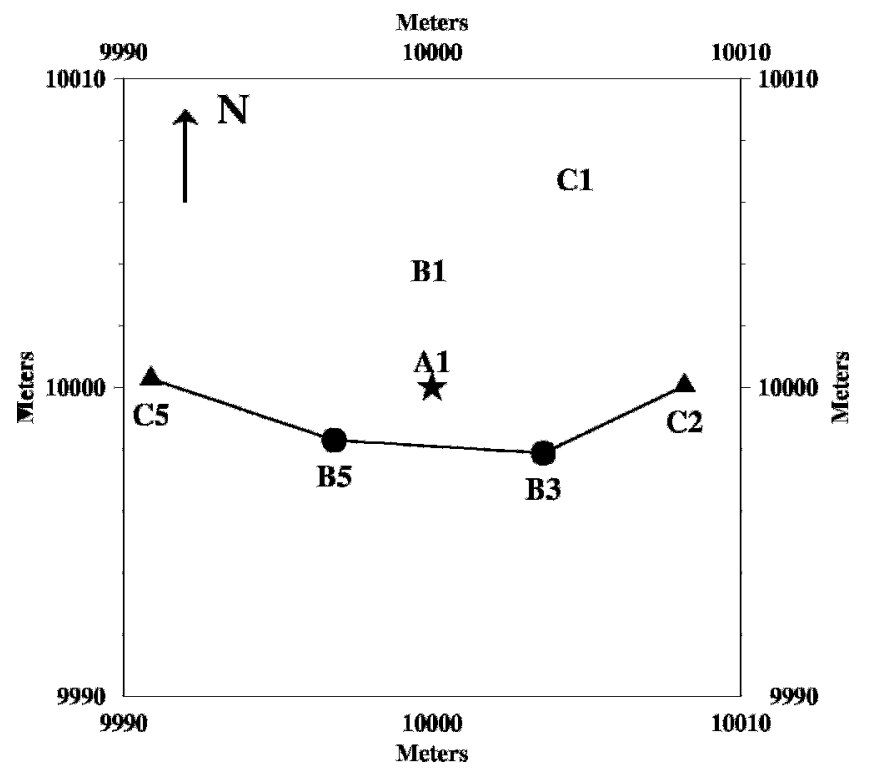

Figure 2. Enlargement of the central wellfield. The tomograms are computed for wells C5 to B5, B5 to B3, and $\mathrm{B} 3$ to $\mathrm{C} 2$, composing a cross-section through the well field.

\section{Data Acquisition and Survey Design}

Crosshole GPR tomography is used to map twodimensional velocity changes between two wells. We used a Mala Ramac Borehole system with $250 \mathrm{MHz}$ antennas to acquire the data. The receiving antenna was held fixed in one well while the transmitting antenna was lowered in the other well. The transmitting antenna produced a signal at $0.05 \mathrm{~m}$ intervals down the well. After this antenna reached the bottom depth, usually the depth of the well, the fixed receiving antenna was then lowered $0.2 \mathrm{~m}$, the transmitting antenna was raised to the top of the well, then lowered as before. The process was repeated until the receiving antenna had been lowered to the maximum depth. This geometry enables radar energy to repeatedly sample the space between the wells.

We present data from three well pairs: C5-B5, B5B3, and B3-C2 (Fig. 2). These well pairs form a contiguous profile between well $\mathrm{C} 5$ and $\mathrm{C} 2$, a straight line distance of about $17.3 \mathrm{~m}$. Wells C5 and B5 are $6.26 \mathrm{~m}$ apart, B5 and B3 are $6.79 \mathrm{~m}$ apart, and $\mathrm{B} 3$ and $\mathrm{C} 2$ are $5.06 \mathrm{~m}$ apart. We chose these three well pairs to analyze because they share common wells; C5-B5 and B5-B3 share well B5 and B5-B3 and B3-C2 share well B3. We can compare the results of the tomography at these common wells to ensure that the inversions are consistent.

Table 1 lists the number of receiver gathers for each well pair and the approximate number of traces per gather. The number of traces per gather varies between well pairs because the well depths are different. Each trace of the gather consists of 32 stacks with 1024 samples per trace. The sampling frequency of the Ramac system was $2,515.15 \mathrm{MHz}$ or about $0.4 \mathrm{~ns}$ per sample.

As part of the tomography experiment, three other types of data were collected: an air wave record; a surface walkaway; and zero-offset profiles down the well. For the surface walkaway, one antenna was fixed vertically at the surface, then the other antenna was moved away in $1.0 \mathrm{~m}$ intervals. The surface walkaway was used to determine the start time of the signal $t_{0}$. A line is fitted to the first arrival times. The time-axis intercept is the $t_{0}$ correction. At the start of each day's acquisition, a surface walkaway was collected to determine $t_{0}$.

The air wave record consists of many traces with the antennas positioned vertically at the wells. These data provide a check to the start time of the survey determined from the surface walkaway profiles. The velocity of EM energy in air and the distance between the wells is known, so we can compute the travel time between the wells. The start time is the difference between the signal's arrival time and the predicted travel time for the antenna (well) separation.

The temperature at the site changes throughout the day resulting in time drifts in the instrument. Further, the instrument will record different $t_{0}$ times on different days. Two methods were used to correct for instrument drift. The depth of the last receiver gather from the previous day was reoccupied and a receiver gather was acquired to directly compare the arrival times between the two days. The necessary corrections were made to align these arrivals. To measure daily instrument drift, zero-offset profiles were collected at the beginning of each tomographic acquisition period. Additionally, a zero-offset profile was collected at the end of the day's acquisition if possible. The zero-offset profile records the travel times for transmitter and receiver pairs at approximately the same elevation. The acquisition took about 15 minutes, so that instrument drift was assumed to be negligible. Each receiver gather had a zero-offset trace where the transmitter and the receiver antennas were at the same locations as in the zero-offset profile. We compared this zero-offset trace with the appropriate trace from the initial zero-offset profile to determine the time compensation for instrument drift over the course of the day (Fig. 4).

\section{First Arrival Picking}

After applying the time corrections to the data and checking for consistency, we picked the first arrival times. Before picking, we bandpass filtered the tomography data between 20 and $300 \mathrm{MHz}$ to remove 
a) Journal of Environmental and Engineering Geophysics

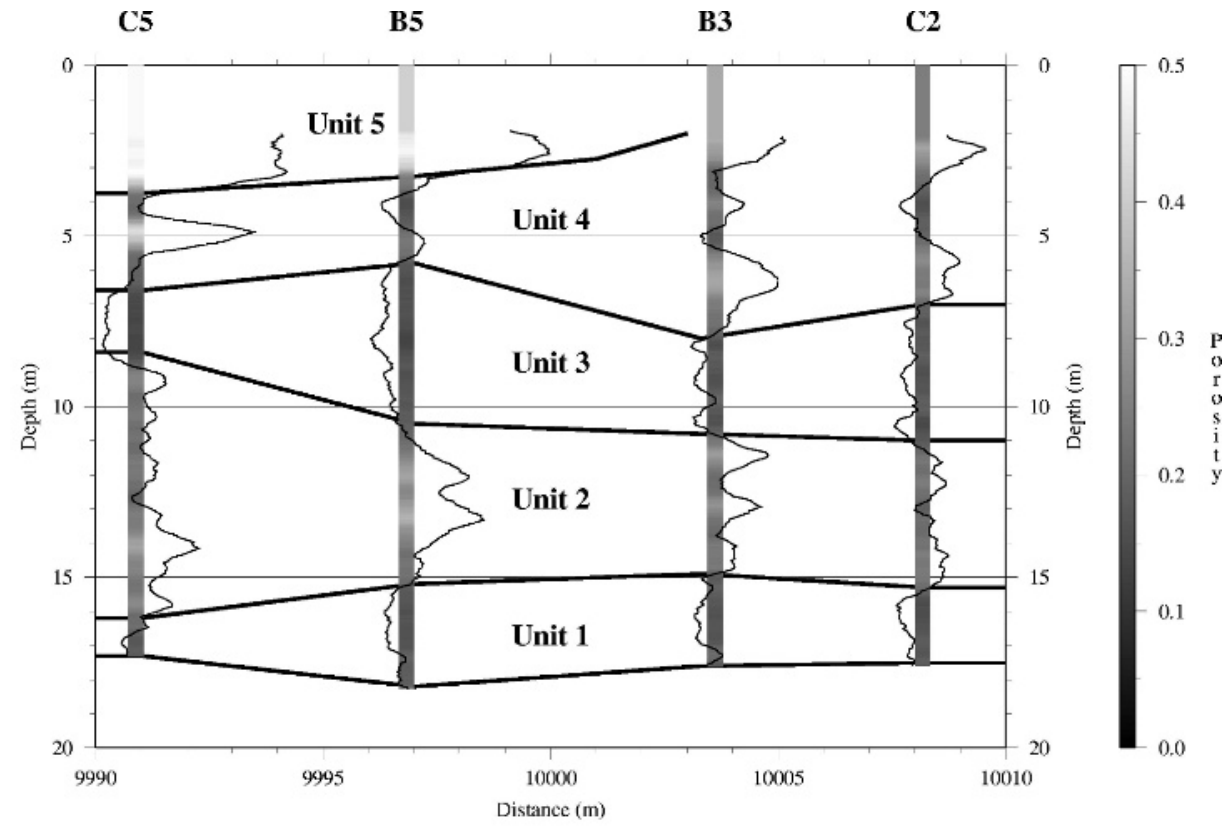

b)

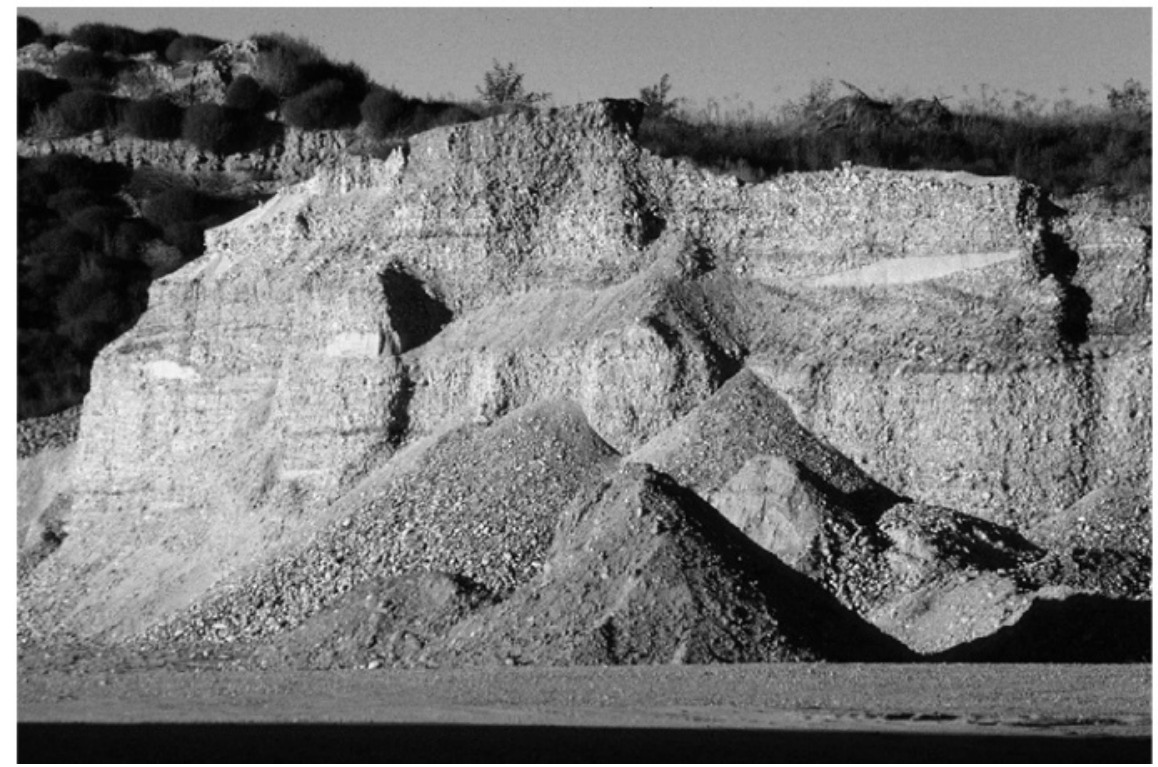

Figure 3. (a) Neutron-derived porosity logs and the stratigraphy based on these logs at the BHRS. (b) Photograph of a nearby gravel pit that is an analog to the BHRS.

unwanted noise. We used a zero-phase filter so as not to shift the travel times. No other processing was applied to the data before picking the arrival times.

To pick the first arrivals, we used an automatic picking routine to select the arrival time of the first peak of the wavelet. Manually selecting the first arrivals would have been too time consuming. We picked the first peak because it was easily seen above the noise level in the data. We then shifted the time of the first peak by one-quarter of the period $(\sim 2.1 \mathrm{~ns})$ of the dominant frequency $(\sim 120 \mathrm{MHz})$ of the data to align the time pick with the onset of the radar energy. To confirm the accuracy of these picks, we compared the travel times directly to the traces (Fig. 5). This process was iterated until we were satisfied that the first arrival time picks were accurate.

\section{Tomographic Inversion}

Tomographic method

To determine the velocity field between the wells, a curved ray, nonlinear tomographic inversion method 
Clement and Barrash: Crosshole Radar Tomography

Table 1. Data parameters.

\begin{tabular}{lrcr}
\hline \hline & C5B5 & B5B3 & B3C2 \\
\hline Gathers & 95 & 101 & 92 \\
Traces & 378 & 407 & 410 \\
\hline
\end{tabular}

was implemented (Aldridge and Oldenburg, 1993). Because the forward operator uses curved rays, the path lengths are dependent on the velocity model. Solving for small changes in the slowness model corresponding to traveltime differences between the observed data and the calculated values linearizes the problem. Using more physically realistic curved rays, as opposed to the simple straight ray approximation, makes the problem more difficult to solve. However, the results should be a better estimate of the subsurface velocity distribution.

The forward operator computes the travel time between each source and receiver integrating along the

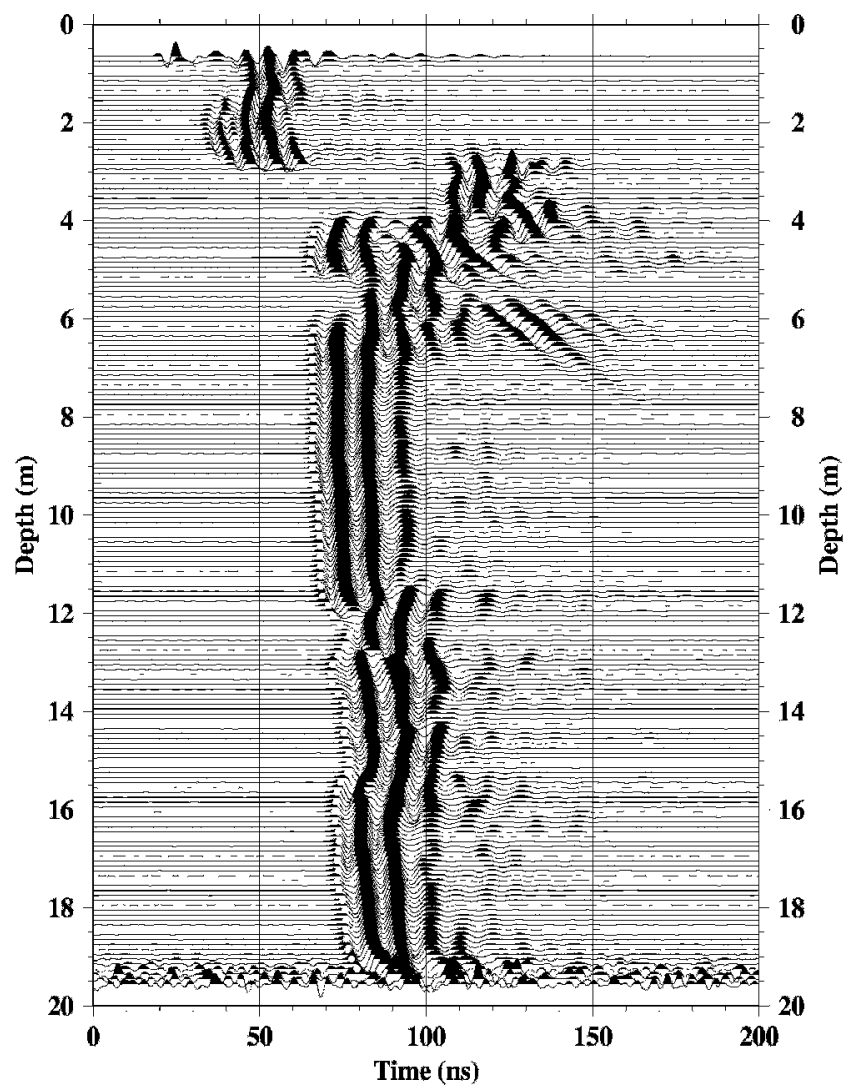

Figure 4. Zero-offset profile from panel C5-B5 showing travel time picks corresponding to the zero-offset traces from each receiver gather. The early arriving energy in the upper 2.5 meters corresponds to energy propagating through the air and the vadose zone.

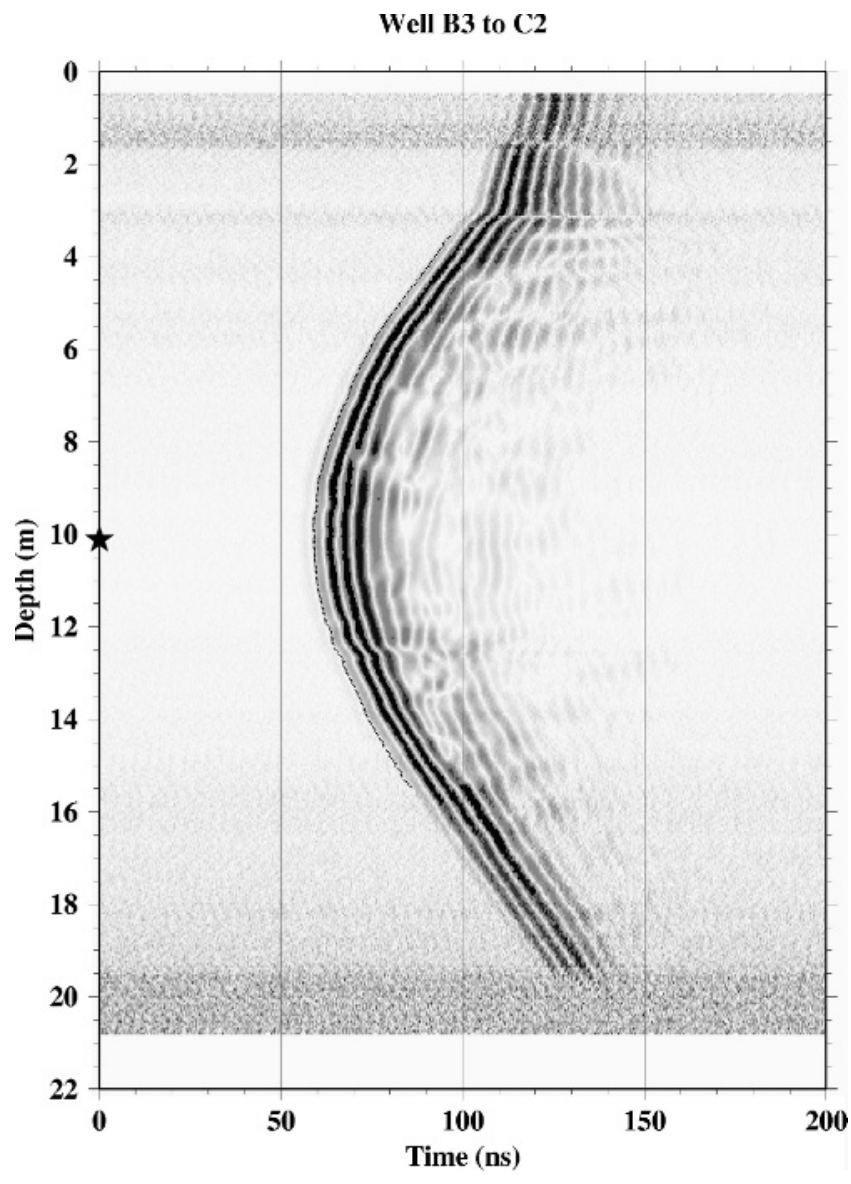

Figure 5. Receiver gather from $10.12 \mathrm{~m}$ depth in from well pair B3 to C2 showing travel time picks (black line) superimposed on the gather.

ray path (Aldridge and Oldenburg, 1993):

$$
\mathbf{t}=\int_{\mathrm{L}} \mathbf{s d l}
$$

The algorithm computes the travel time of the first arriving energy to each node of the 2-D grid using a finite-difference approximation to the eikonal equation (Vidale, 1988). For this study, we chose a node spacing of $0.1 \mathrm{~m}$. The algorithm back-projects the ray from the receiver to the source along the gradient of the traveltime field to compute the path lengths of the ray through each cell (Aldridge and Oldenburg, 1993). These path lengths are the values of the Jacobian matrix $\mathbf{G}$, and are used by the inversion routine.

In tomography, the problem is usually ill-posed and ill-conditioned. In other words, some of the cells in the model are poorly sampled and small data errors can cause large model parameter errors. The result is that $\mathbf{G}$ is singular and an inverse does not exist. To overcome 
Journal of Environmental and Engineering Geophysics

a)

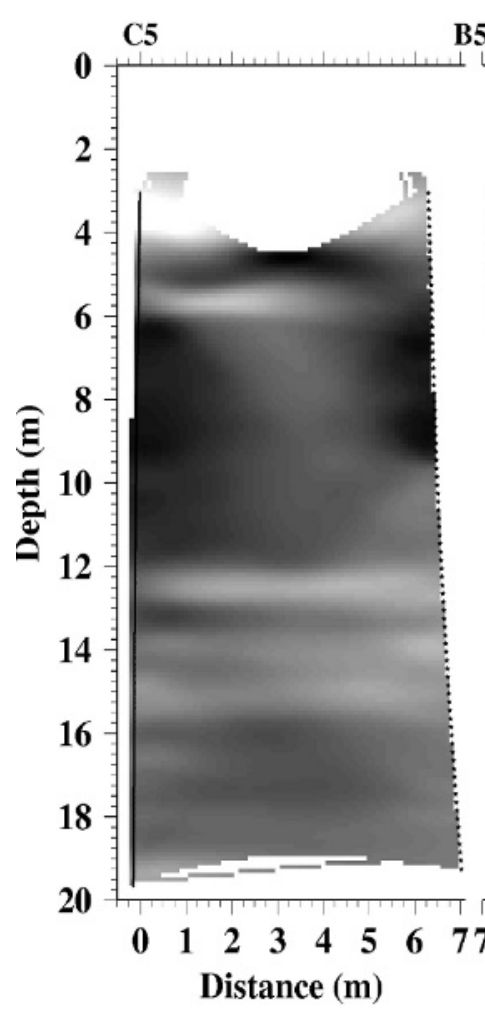

b)

B3

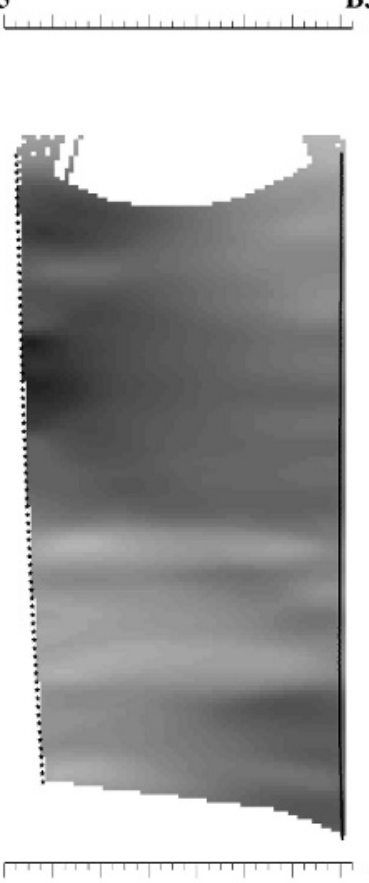

C 2
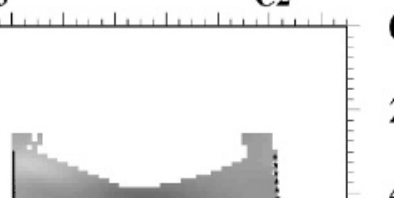

4

6

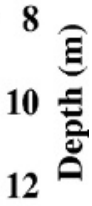

14

16

18 20

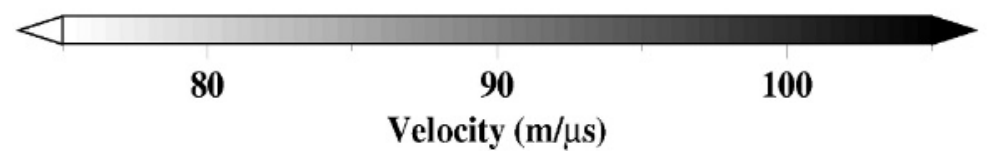

Figure 6. Tomograms of the EM velocities between the three well pairs: C5-B5, B5-B3, and B3-C2.

this difficulty, the equations can be reformulated into the weighted, damped, least squares solution (Menke, 1989):

$$
\begin{aligned}
\mathbf{m}_{\text {est }}= & \mathbf{m}_{\text {ref }}+\left(\mathbf{G}^{\mathrm{T}} \mathbf{W}_{\mathbf{e}} \mathbf{G}-\lambda^{2} \mathbf{W}_{\mathbf{m}}\right)^{-1} \\
& \mathbf{G}^{\mathrm{T}} \mathbf{W}_{\mathbf{e}}\left(\mathbf{G} \mathbf{m}_{\mathrm{ref}}-\mathbf{d}_{\mathbf{o b s}}\right)
\end{aligned}
$$

Here, $\mathbf{m}_{\text {est }}$ is the solution, an estimate of the true model parameters, slowness (velocity) in travel-time tomography. $\mathbf{m}_{\text {ref }}$ is an initial guess for the slowness (velocity) model and the reference model for the inversion, $\mathbf{W}_{\mathbf{e}}$ is the data weighting matrix, $\mathbf{W}_{\mathbf{m}}$ is the model weighting matrix, and $\lambda$ is a parameter adjusting the relative importance of model fit or data fit. $\mathbf{d}_{\mathbf{o b s}}$ are the observed travel-times.

In nonlinear tomography, the solution is iterative. The solution to the nonlinear problem is (Aldridge and Oldenburg, 1993):

$$
\begin{aligned}
\mathbf{m}_{\mathbf{n}+1}= & \mathbf{m}_{\mathbf{n}}-\left(\mathbf{G}^{\mathrm{T}} \mathbf{W}_{\mathbf{e}} \mathbf{G}-\lambda^{2} \mathbf{W}_{\mathbf{m}}\right)^{-1} \\
& \left(\mathbf{G}^{\mathrm{T}} \mathbf{W}_{\mathbf{e}}\left(\mathbf{G m}-\mathbf{d}_{\mathbf{o b s}}\right)-\mathbf{W}_{\mathbf{m}}\left(\mathbf{m}_{\mathbf{n}}-\mathbf{m}_{\mathrm{ref}}\right)\right) .
\end{aligned}
$$

For this analysis, $\mathbf{W}_{\mathbf{e}}$ is a diagonal matrix with the reciprocal of the distance between the transmitter and the receiver as the elements. $\mathbf{W}_{\mathbf{m}}$ consists of the finitedifference approximation to the first derivative (1 -1) weighted by 15 in the horizontal direction and 5 in the vertical direction. The anisotropic weighting assumes that the stratigraphy is more continuous horizontally than vertically (e.g., Barrash and Clemo, 2002). A constant of 0.01 is added to the diagonal of $\mathbf{W}_{\mathbf{m}}$ to ensure stability of the inversion. In linearized inversions, a key to finding the global minimum is having a starting model close to the actual Earth model. We use a starting model $\mathbf{m}_{\mathbf{0}}$ based on results from zero offset profiles. The model is split into an upper layer with a velocity of $0.14 \mathrm{~m} / \mathrm{ns}$; this layer represents the vadose zone. Below, the velocity is $0.08 \mathrm{~m} / \mathrm{ns}$; this layer represents the aquifer. A gradational boundary, with the velocity linearly decreasing from $0.14 \mathrm{~m} / \mathrm{ns}$ at $1.8 \mathrm{~m}$ to $0.08 \mathrm{~m} / \mathrm{ns}$ at $2.2 \mathrm{~m}$ separates the two layers. The gradational boundary allows the finite-difference solver to more accurately model the energy propagating across this 
Clement and Barrash: Crosshole Radar Tomography

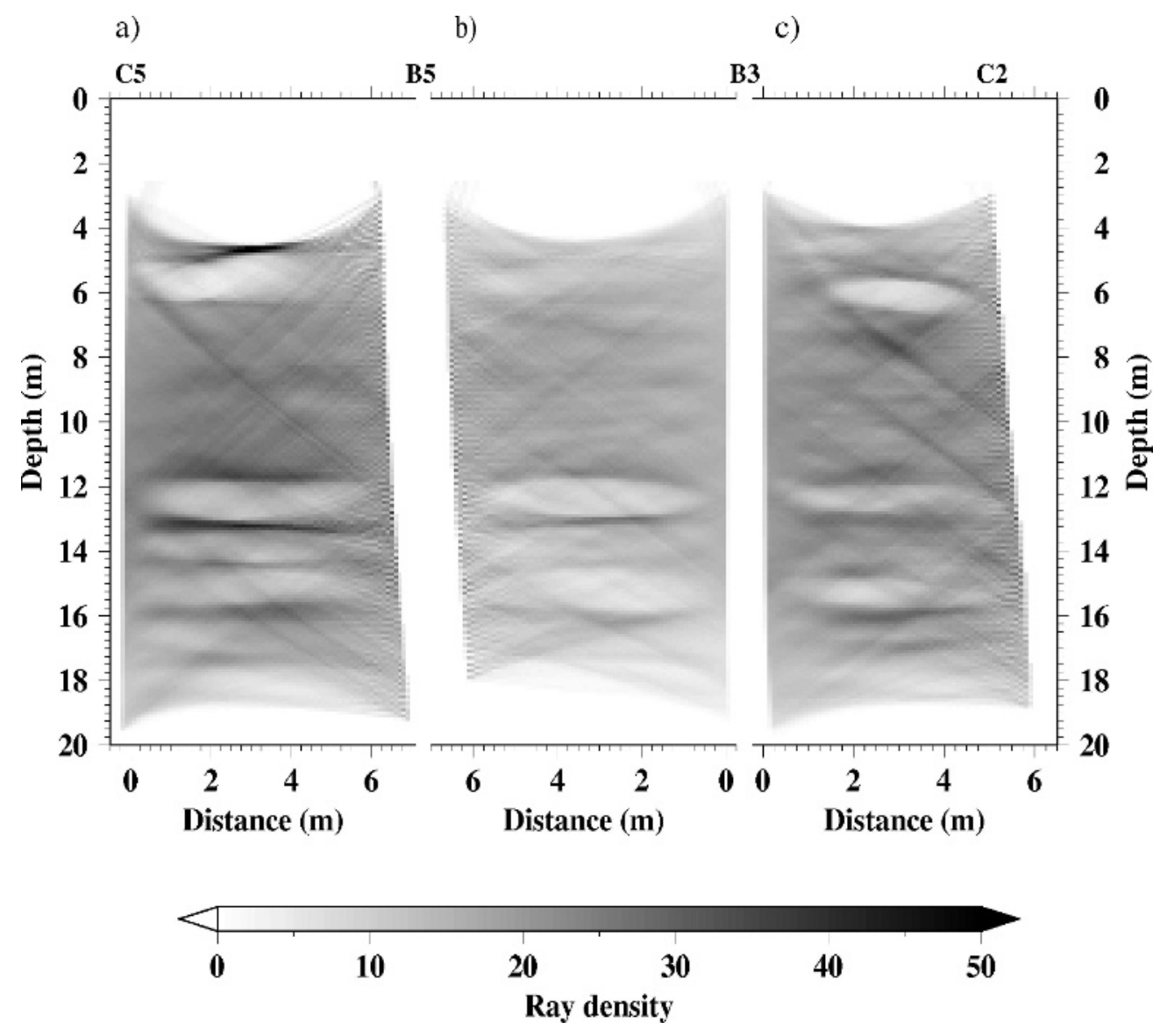

Figure 7. Ray density diagrams for the tomograms in Fig. 6.

boundary. The reference model, $\mathbf{m}_{\mathbf{r e f}}$, is the same as the starting model. The inversion routine iteratively updates the slowness model based on Eq. 3 until the stopping criteria are met.

Ideally, the tomography routine stops when the data misfit is about the same level as the noise in the data or the number of iterations exceeds a user-defined amount. Since noise estimates in our data are poorly known, we stopped the inversion when the weighted RMS residual error was less than $0.1 \mathrm{~ns}$. In this case, the weighted RMS residual error is the root mean square of the residuals weighted by the data error. The inversion uses an iterative solver, LSQR, to find the slownesses (Paige and Saunders, 1982), because the matrices in
Eq. 3 are too large to solve by singular value decomposition. The LSQR solver uses a maximum of 150 iterations or stops when the difference between two LSQR iterations is less than $1 \times 10^{-6}$. The LSQR routine is fast, but the inverse of the Jacobian matrix is not computed. Without the Jacobian matrix inverse, formal estimates of resolution and covariance, based on linear inverse theory, are not possible. The program calculates the slowness values for the plane between the two wells, then outputs the calculated $2 \mathrm{D}$ velocity distribution.

$\underline{\text { Results }}$

Each tomogram displays the EM velocity between the wells (Fig. 6). The input data contain only trans-

Table 2. Inversion statistics.

\begin{tabular}{lcccccc}
\hline \hline Well pair & RMS residual (ns) & $\begin{array}{c}\text { Weighted RMS } \\
\text { residual (ns) }\end{array}$ & $\begin{array}{c}\text { Mean residual } \\
(\mathbf{n s})\end{array}$ & $\begin{array}{c}\text { Number of rays/ } \\
\text { number of picks }\end{array}$ & Iterations & Number of cells \\
\hline C5-B5 & 0.684 & 0.093 & 0.259 & $18,070 / 18,076$ & 3 & 25,134 \\
B5-B3 & 0.373 & 0.047 & 0.056 & $12,913 / 12,953$ & 3 & 24,265 \\
B3-C2 & 0.525 & 0.088 & 0.096 & $14,595 / 14,628$ & 2 & 22,896 \\
\hline
\end{tabular}


a)

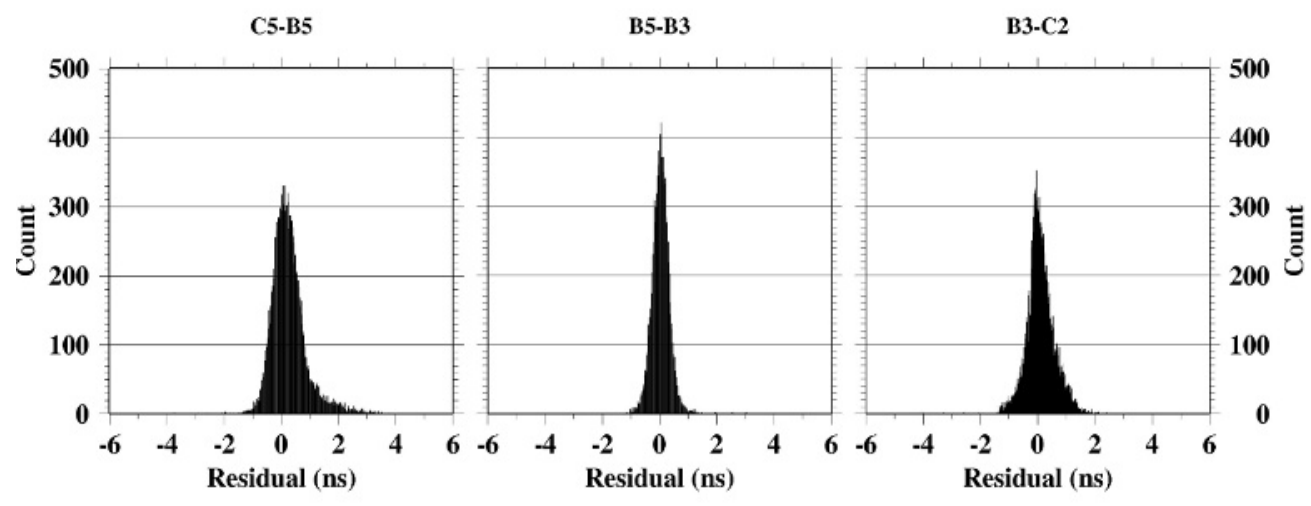

b)
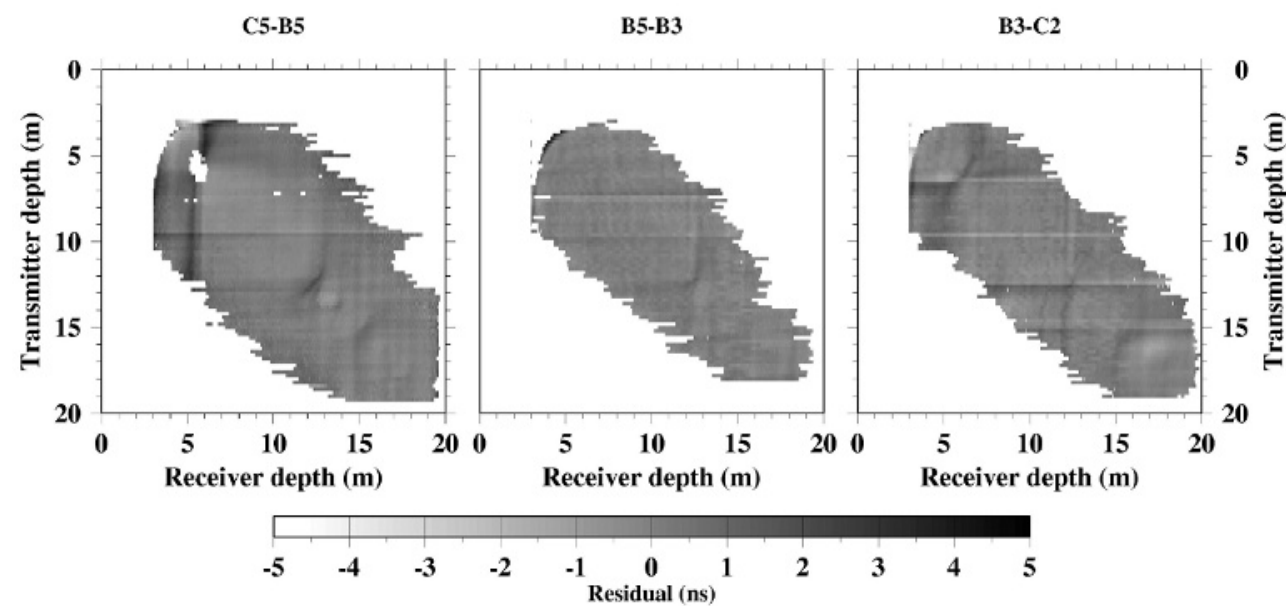

Figure 8. Residual times from the inversion. (a) Histograms showing the temporal distribution of the residuals. (b) Plots showing the spatial distribution of the residuals.

mitter and receiver locations below $3.0 \mathrm{~m}$ to avoid refractions from the air/ground interface. To better match the velocities along the common wells, we had to shift the subsurface location of the wells from their position as measured by deviation logging. We then deflected the horizontal locations at depth along a smooth curve. The curve was parameterized by the fixed surface location of the well, the depth at which the well shifts from the measured horizontal location, and the total amount of deflection at the bottom of the well. Repeatable, calibrated deviation logs had an error generally less than $1 \mathrm{~m}$ at the bottom of the wells. We kept the shifts in location within this range. Whenever we adjusted a well location, we ensured that every well common to two panels had the same position.

In general, the tomograms indicate a relatively constant, high velocity of about 0.09 to $0.10 \mathrm{~m} / \mathrm{ns}$ between 6 to $12 \mathrm{~m}$ depth. These velocities are consistent with the relatively low porosity and its low variation in Unit 3. In the C5-B5 tomogram, a low velocity zone of about $0.08 \mathrm{~m} / \mathrm{ns}$ exists between about 5 to $6 \mathrm{~m}$ depth, and in the B3-C2 tomogram a similar low velocity zone exists between 5.5 and $6.5 \mathrm{~m}$ depth. These zones align with lenses occurring in Unit 4. In the three panels, low velocities are observed about 3 to $4 \mathrm{~m}$ depth, consistent with the sands of Unit 5 between wells C5 and B5 and a sand lens between wells B3 and C2. Between 12 to $16 \mathrm{~m}$, the tomograms have alternating low and high EM velocity zones indicating the greater porosity variation of Unit 2; some of these zones appear to extend across the panels. In panels C5-B5 and B5-B3, three layers with velocities of about $0.085 \mathrm{~m} / \mathrm{ns}$ appear: at 12 to $13 \mathrm{~m}$, 13.5 to $14.5 \mathrm{~m}$, and 15 to $16 \mathrm{~m}$. The velocity of the 13.5 to $14.5 \mathrm{~m}$ layer gradually increases to about $0.09 \mathrm{~m} / \mathrm{ns}$ at about $3 \mathrm{~m}$ across the panel. In panel B3-C2, only two $0.085 \mathrm{~m} / \mathrm{ns}$ layers are seen at about 12 to $13 \mathrm{~m}$ and about 15 to $16 \mathrm{~m}$; the layer centered at $14 \mathrm{~m}$ is not observed. The velocities in the panels tend to decrease from the C5-B5 panel to the B3-C2 panel. This velocity change appears smooth, with the B5-B3 panel showing 
Clement and Barrash: Crosshole Radar Tomography

a)

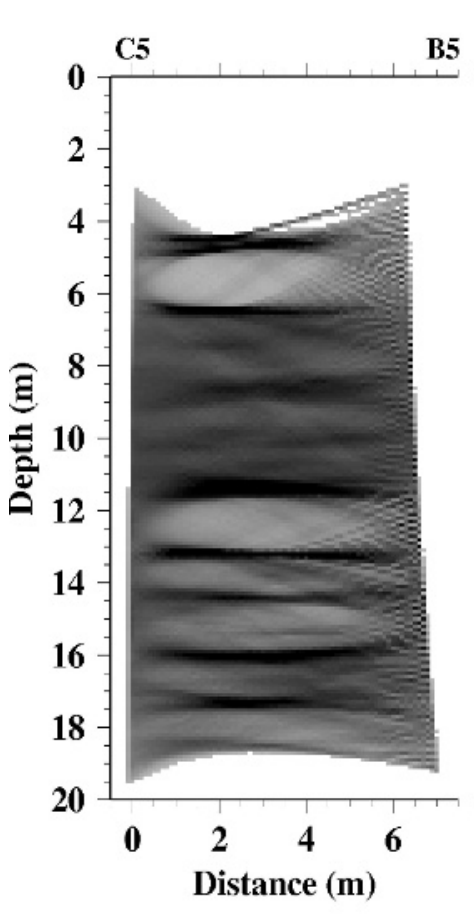

b)

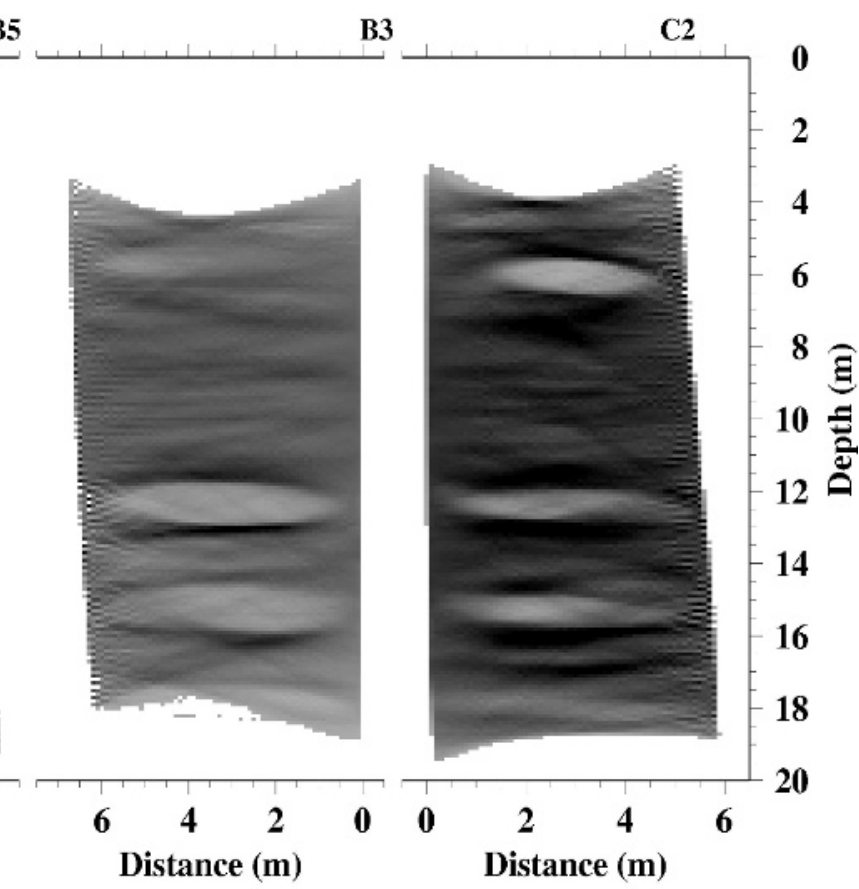

\section{$\begin{array}{lll}0.71 & 0.72 & 0.73\end{array}$}

Figure 9. The diagonal elements of the resolution matrix for the tomograms of Figure 6. Light zones indicate low resolution.

a velocity decrease from west to east (left to right), consistent with the overall trend.

To look at the tomographic sampling of the subsurface, Fig. 7 shows the ray densities for each cell. The ray density is defined as the total length of all the rays crossing a cell divided by the cell length $(0.1 \mathrm{~m})$. Areas with high ray densities have been well sampled by the radar energy. Those areas with low ray density have been poorly sampled. As Fig. 7 shows, areas with low velocity have a low ray density. By Fermat's Principle, the first arrivals will tend to travel in higher velocity regions, so a bias towards sampling the faster zones is inherent in first arrival tomography.

\section{$\underline{\text { Inversion statistics }}$}

To estimate the reliability of the inversion, Table 2 presents some statistics from the tomographic inversion. In each inversion, the program used greater than $99.7 \%$ of the travel time picks. The data fit is best for panel B5B3 and worst for panel C5-B5. All inversions converged within three iterations.

Figure 8 shows the distribution of the travel time residuals. In Fig. 8a, histograms of the residuals have an approximate Gaussian distribution. The residuals range from -4.6 to $3.9 \mathrm{~ns}$ for the $\mathrm{C} 5-\mathrm{B} 5$ inversion, -1.7 to $5.4 \mathrm{~ns}$ for the B5-B3 inversion, and -4.0 to $3.4 \mathrm{~ns}$ for the B3-C2 inversion. Figure $8 \mathrm{~b}$ plots the residuals in relation to the receiver/transmitter locations. Vertical stripes on this plot indicate that a specific receiver has a strong misfit; horizontal stripes indicate a poor fit to a transmitter. The largest misfits in the inversions are where the receiver and transmitter are in the upper $5 \mathrm{~m}$ or so. This location is not surprising; the velocity change across the water table is strong, so refractions may interfere with the direct arrivals causing the poor fit.

\section{Uncertainty estimates}

An important aspect of model analysis is to estimate the uncertainty of the results. One method of appraisal is to investigate the resolution and covariance matrices. However, the size of the models and the number of data are large, so inversion requires iterative methods that do not compute the Jacobian matrix inverse necessary for formal resolution analysis. Additionally, for linearized, iterative inversion, formal definitions of resolution and covariance do not exist. Fortunately, methods to compute the approximate values for the diagonal elements of the resolution 
Journal of Environmental and Engineering Geophysics

a)

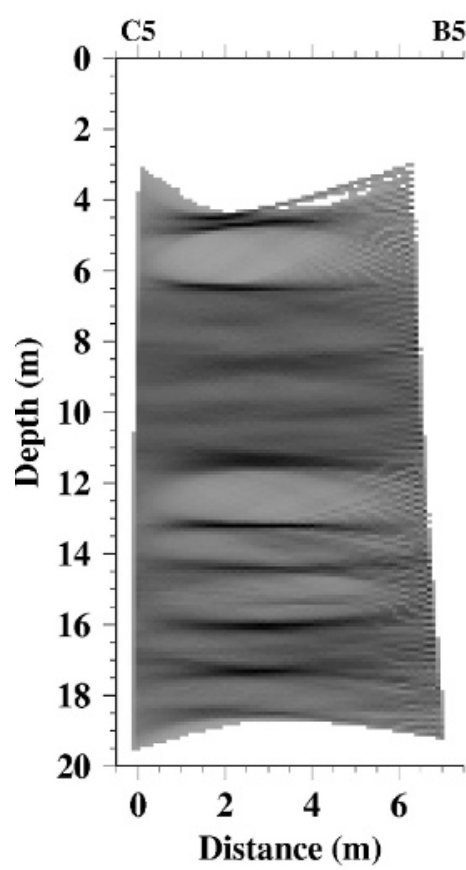

b) B5

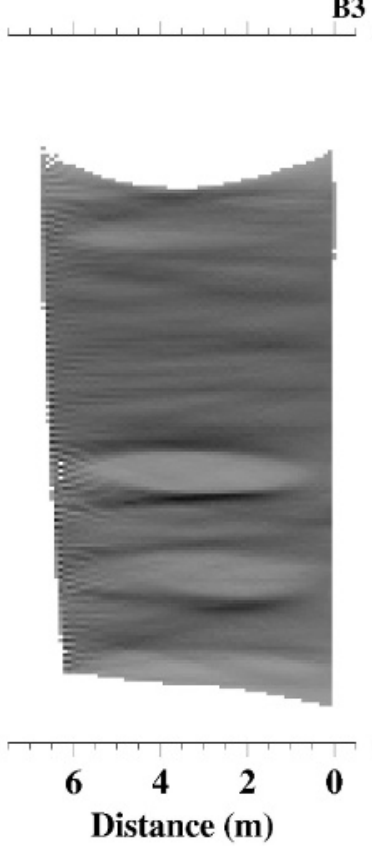

c)
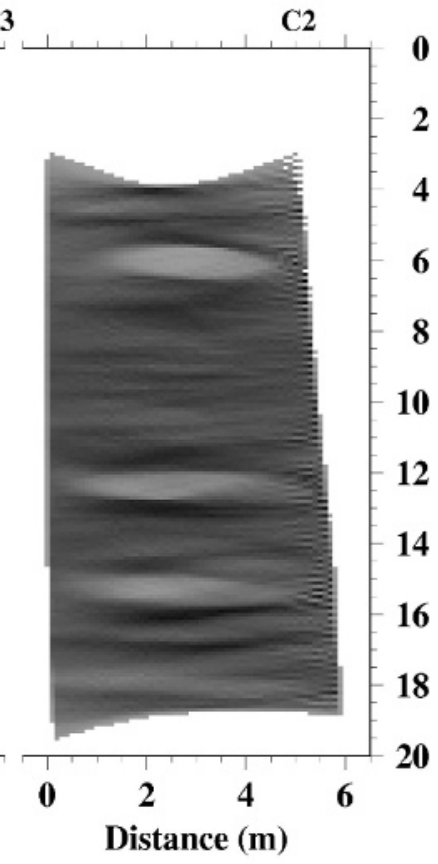

0.0012

0.0010

0.0011

$\mu s^{2} / m^{2}$

(2)

\section{嗃}

4 6 8

(1)

Figure 10. The diagonal elements of the covariance matrix for the tomograms of Figure 6. Light zones indicate low variance.

(Fig. 9) and covariance (Fig. 10) matrices exist (Nolet et al., 1999). For the resolution matrix, these values ideally range between 0 and 1 and may be thought of as the probabilities that the inversion has correctly resolved the velocity for that cell (Berryman, 2000). Although the range of resolution values is small, the low velocity zones in the velocity model clearly are more poorly resolved than the high velocity regions. From Fig. 9, a strong correlation between resolution and the ray density is obvious. This correlation suggests that the easily computed ray densities are a good indicator of the resolution matrix and a rough guide to model resolution.

The diagonal elements of the covariance matrix are the slowness variances and show the uncertainty of the slowness estimates (Fig. 10). The variances range from about $0.00095 \mu \mathrm{s}^{2} / \mathrm{m}^{2}$ (a standard deviation of $0.031 \mu \mathrm{s} / \mathrm{m}$ ) to about $0.0012 \mu \mathrm{s}^{2} / \mathrm{m}^{2}$ (a standard deviation of $0.035 \mu \mathrm{s} / \mathrm{m}$ ). Converting the standard deviations to velocity units gives a range of $0.0323 \mathrm{~m} / \mathrm{ns}$ to $0.0286 \mathrm{~m} / \mathrm{ns}$ compared to velocities ranging between $0.080 \mathrm{~m} / \mathrm{ns}$ to $0.105 \mathrm{~m} / \mathrm{ns}$. However, the variances are relative to the slowness and the conversion from slowness to velocity is non-linear. Thus, a complicated relationship exists between the variances computed for the slownesses and the variance of the velocities. Comparing the variances with the diagonal values of the resolution, zones with lower variance have poorer resolution than those zones with high variance. Figures 9 and 10 demonstrate the well-known trade-off between variance and resolution (Menke, 1989).

Figure 11 shows a direct comparison of the velocities at the common wells. The velocities are similar, except between about $5 \mathrm{~m}$ to $8 \mathrm{~m}$ depth. In this zone, the velocities differ by a maximum of about $0.005 \mathrm{~m} / \mathrm{ns}$. For well B5, the velocity change is in different directions; slowing in the B5-B3 tomogram, but increasing in the C5-B5 tomogram. Below $8 \mathrm{~m}$ depth, the velocities are about the same magnitude and the velocity changes occur at similar depths and in the same direction (towards larger or smaller velocities). This match indicates that the velocities are internally consistent and indicates that the results are robust among the different panels.

\section{Interpretation}

The tomograms show estimates of the velocity distribution in the unconfined aquifer at the BHRS. 
Clement and Barrash: Crosshole Radar Tomography

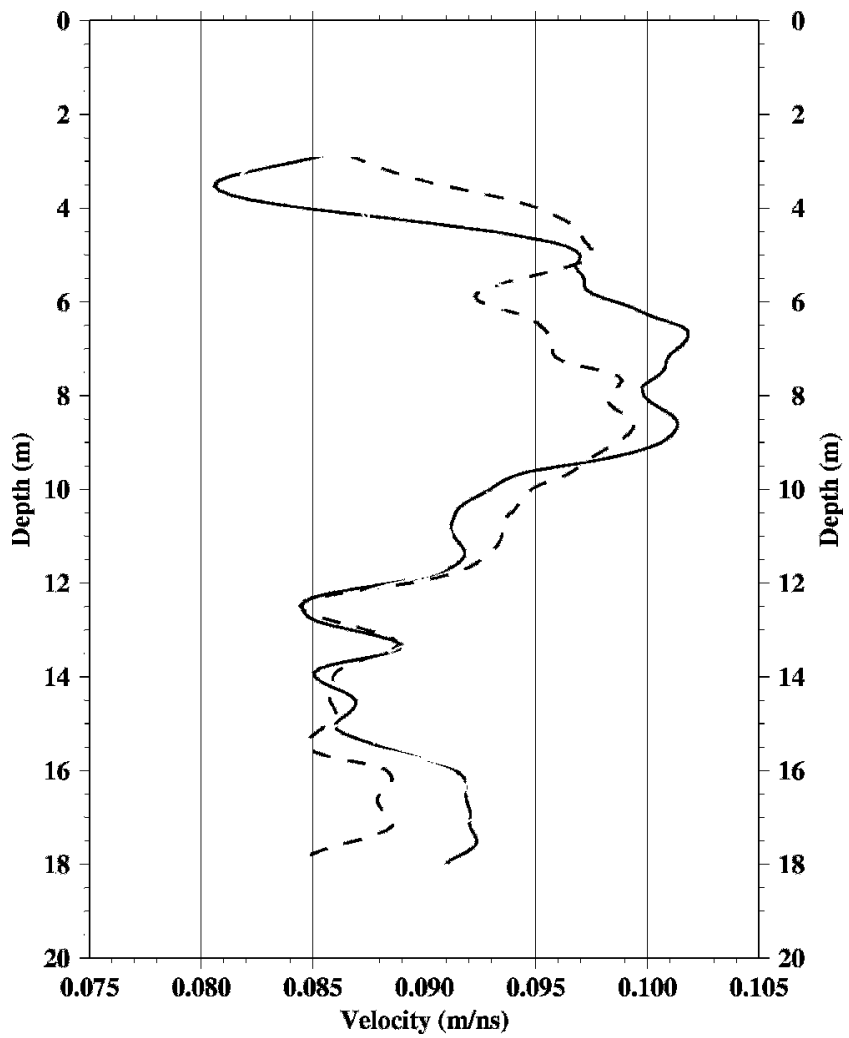

Figure 11. Velocities near the wells from the tomogram panels. The black lines are for well B5; solid line from tomogram C5-B5; dashed line from tomogram B5-B3. The gray lines are for well B3; solid line from tomogram B3-C2; dashed line from tomogram B5-B3. Except for a zone between 5 to $8 \mathrm{~m}$, the velocities are very similar between tomograms.

However, velocity is not the parameter of primary interest to most hydrologists. A more important parameter is hydraulic conductivity. Unfortunately, a relationship between EM velocity and hydraulic conductivity is yet to be discovered. Instead, an inverse relationship between EM velocity and porosity exists. Figure 12 compares the porosity derived from neutron logs and the travel time of the zero offset profile for C5B5. Where porosity is high, the arrival of EM energy is delayed. The longer travel time indicates a slower EM velocity. Between 6 to $12 \mathrm{~m}$ depth, the porosity is relatively low with relatively low variability; the travel times are relatively constant. Below about $12 \mathrm{~m}$, the porosities are relatively higher and more variable; the travel times are also more variable. Water strongly affects the EM velocity; high water content lowers the velocity, whereas low water content increases the velocity. At the BHRS, the mineralogy is reasonably homogeneous (Barrash and Reboulet, 2004), so variations in EM velocity are due to changes in water content. Below the saturated zone, the porosity controls

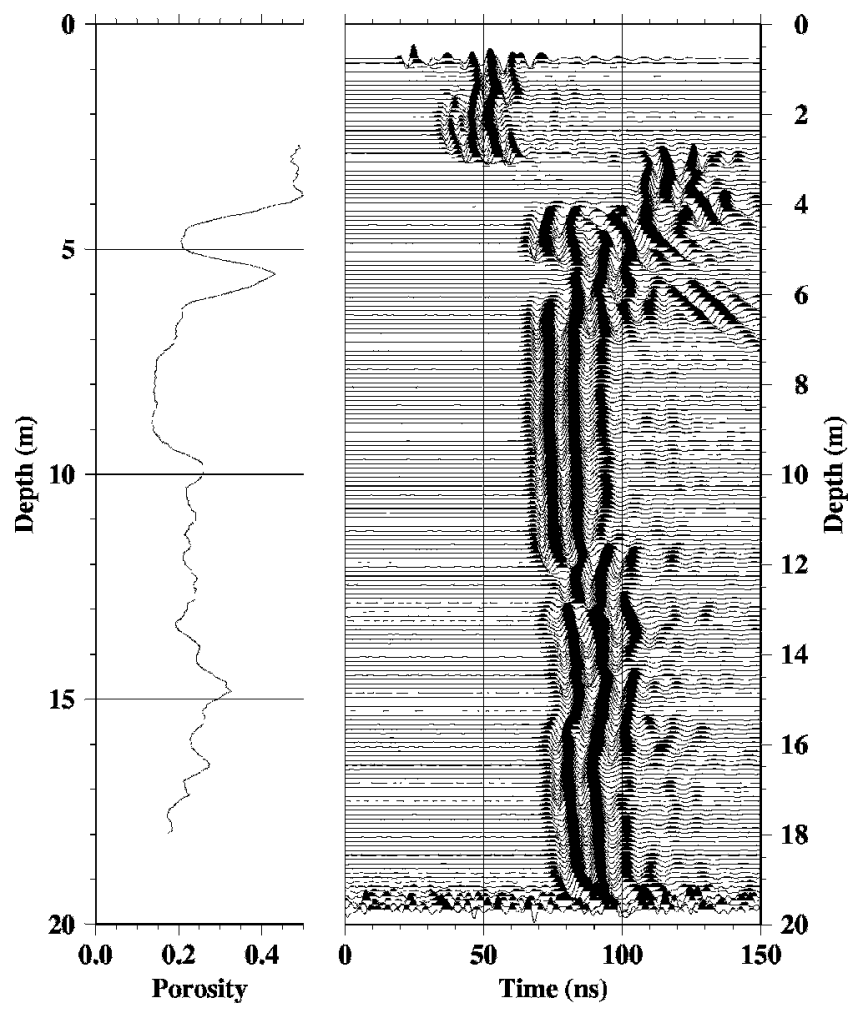

Figure 12. Zero offset profile from well pair C5-B5. Note the strong correlation between porosity and the travel time variations. Long travel times, or slow velocities, correlate with high porosity zones. Black line is for Well C5, gray line is for Well B5. The early arriving energy in the upper $\mathbf{2 . 5}$ meters corresponds to energy propagating through the air and the vadose zone.

the water content. Thus, zones of fast EM velocity indicate zones of low porosity and zones of slow EM velocity indicate high porosity zones.

To determine the porosity, we first converted the EM velocity to the dielectric permittivity using the relation

$$
\kappa=\frac{c^{2}}{v^{2}} .
$$

Next, we converted the dielectric permittivity to the porosity, assuming saturated conditions, using the time propagation model

$$
\theta=\frac{\sqrt{\kappa}-\sqrt{\kappa_{s}}}{\sqrt{\kappa_{w}}-\sqrt{\kappa_{s}}},
$$

where $\kappa_{w}$ is the dielectric permittivity of water (80.36) and $\kappa_{s}$ is the dielectric permittivity of the sediments (4.5) (Gueguen and Palciauskas, 1994). This model is a semiempirical, volume averaging model commonly used to determine porosity in GPR investigations (Knight, 2001). 
Journal of Environmental and Engineering Geophysics

a)

b)

c)
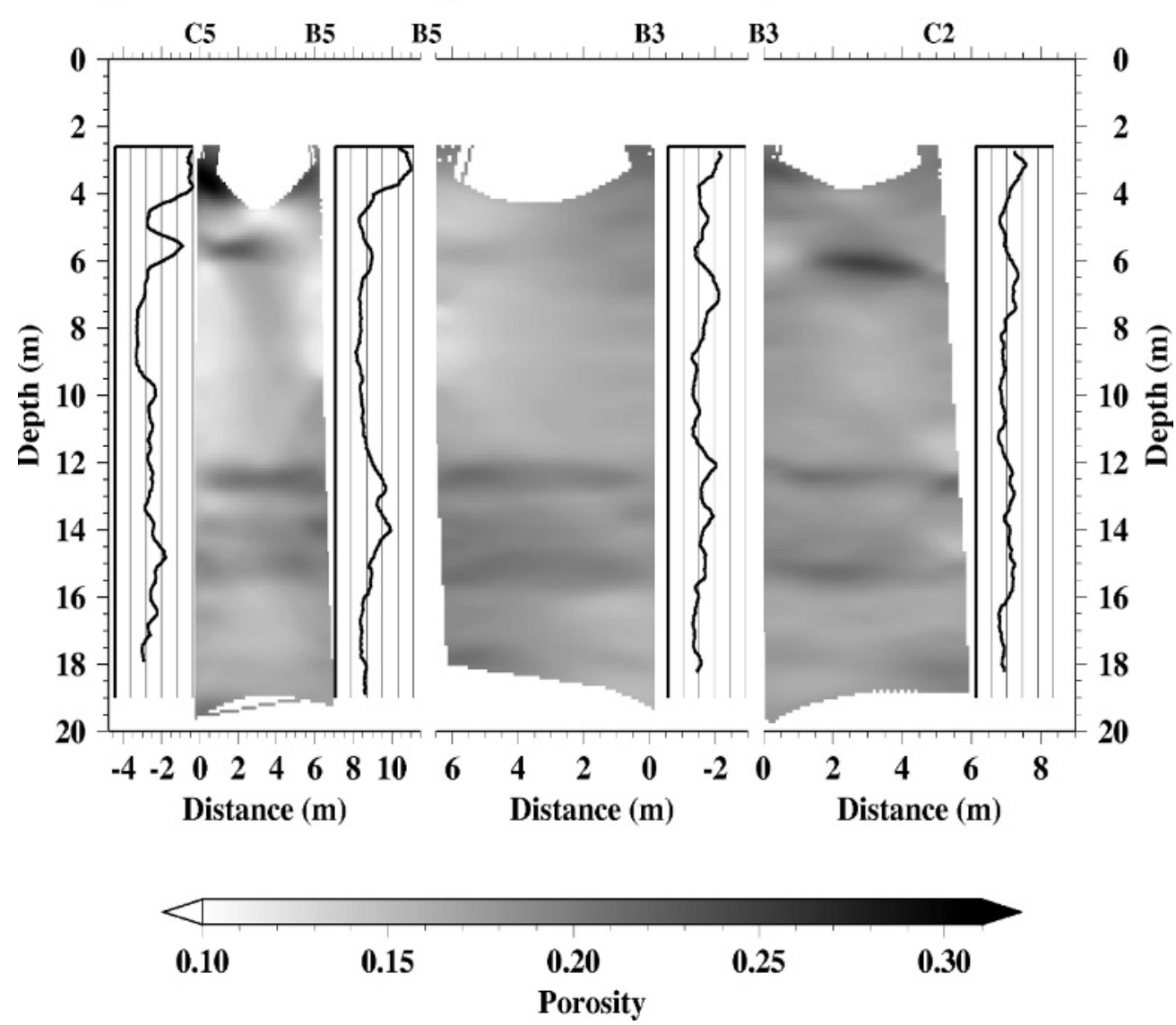

Figure 13. Porosity values derived from the tomograms. The porosities derived from neutron logs are shown at their well locations. The scale on the neutron-derived porosity ranges from 0 to 0.5 ; the vertical grids indicate 0.1 increments.

Figure 13 shows the porosities derived from the EM velocity estimates. As expected, the porosities are high where the velocities are slow (compare Fig. 13 with Fig. 6). Plotted adjacent to the EM velocity-derived porosities are the neutron-derived porosities for each well. Qualitatively, the EM velocity-derived porosities match the neutron-derived porosities. Zones of high porosity, especially in the upper $6 \mathrm{~m}$ of panel C5-B5 and B3-C2 correspond to zones of high porosity measured with the neutron probe. The high porosity zone (Unit 2) between 12 to $15 \mathrm{~m}$ in wells B5 and B3 corresponds to a high porosity layer in the tomograms. Thus, the tomograms provide a $2 \mathrm{D}$ map of the porosity variation.

To look at the porosity magnitudes, Fig. 14 compares the porosity derived from the average of the tomogram velocities within $2 \mathrm{~m}$ of the wells with the neutron-derived porosities measured in the appropriate wells. In general, the tomogram-derived porosities are less than the porosities measured in the wells. When the measured porosity is low, the tomogram-derived porosities are only slightly less than the measured porosities.
This relationship is especially clear between 9 to $11 \mathrm{~m}$ in wells B3 and C2 (Fig. 14c). Alumbaugh et al. (2002), in a similar study, but restricted to the vadose zone, found that the tomography results match reasonable well in the low-moisture zones (low porosity zones in this study), but do not recover the high moisture zones (high porosity zones in this study). They attribute this poor match at the high moisture zones to (1) the insensitivity of crosshole radar to the low velocities of these zones, and (2) the different sampling volumes of the neutron probe compared with the radar energy.

The crosshole radar energy does not sample the region between the wells equally. The zones of high porosity will correspond to low velocity zones in the tomograms. Remember that the radar energy preferentially samples the faster velocities or the lower porosities causing a bias in the results. This bias may explain some of the discrepancy between the two porosity estimates. The sample volume between the crosshole survey and the neutron probe is different. The radar samples a larger volume ( $\sim 1 \mathrm{~m}$ radius of Fresnel zone (Galagedara et al., 
Clement and Barrash: Crosshole Radar Tomography

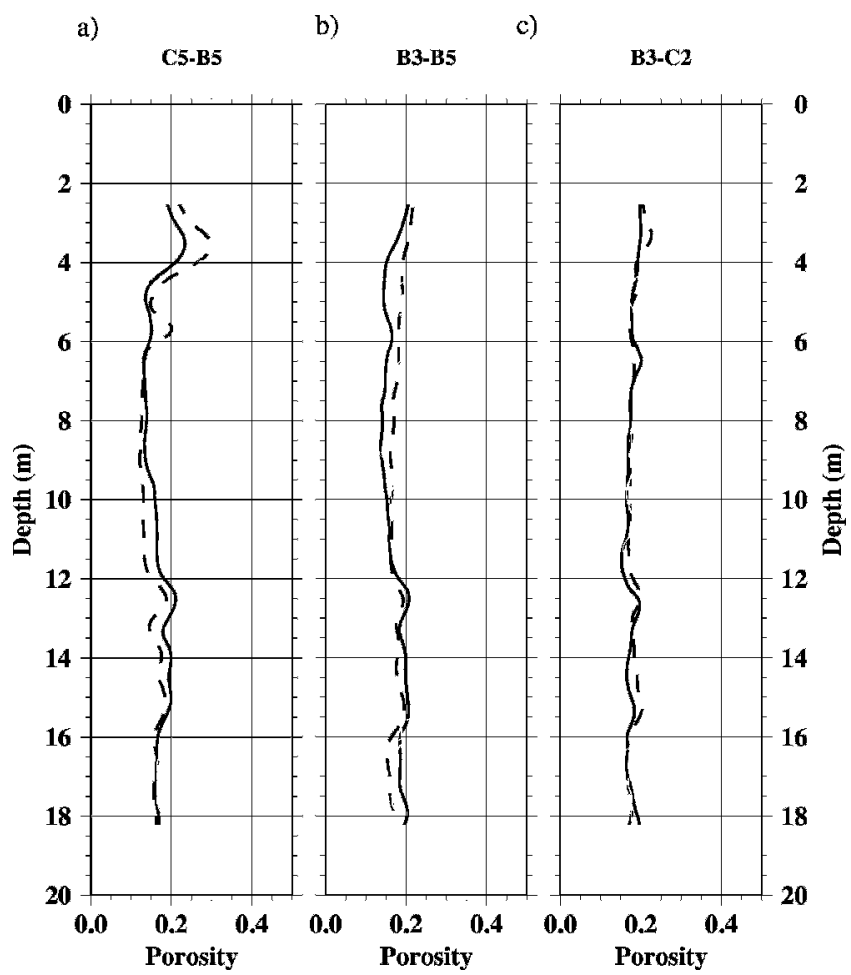

Figure 14. EM-derived porosity (heavy lines) using the time propagator model of Eq. 5 from the velocity information near the wells compared to the neutronderived porosity (light lines). (a) Solid line-B5; dashed line-C5. (b) Solid line-B5; dashed line-B3; (c) Solid line-C2; dashed line-B3. The neutron-derived porosities have been smoothed for easier comparison.

$2003)$ ) than the neutron probe ( $\sim 0.5 \mathrm{~m}$ sampling radius; Keys, 1990), so the radar results would average over a larger volume resulting in less variations and smaller extremes compared to the neutron-derived porosity measurements.

\section{Conclusions}

The tomograms provide a 2-D image of the subsurface along a transect through the BHRS. The EM velocities indicate that the subsurface between 7 to $12 \mathrm{~m}$ depth (Unit 3 ) is relatively homogeneous. Below $12 \mathrm{~m}$ (Unit 2), the tomograms indicate that the subsurface alternates between low and high velocity (high and low porosity) zones across the cross-section. In the tomograms for wells C5-B5 and B3-C2, a low velocity (high porosity) lens near $6 \mathrm{~m}$ depth (sandy lens in Unit 4 ) is modeled. A strong correlation between resolution and the ray density is obvious. This correlation may allow for the use of the easily computed ray densities as a proxy for the resolution matrix. Thus, the ray density plots provide a qualitative estimate of the reliability of the tomograms. An important constraint on the tomograms is that the EM velocities match at their common well. By slightly shifting the wells, the inverted EM velocities reasonably matched at the wells. The porosities derived from the tomograms are similar to the porosities derived from neutron log measurements. The values and variability of the tomogram-derived porosities are smaller than those from the neutron logs; the tomogram-derived porosities are a good match to the lower values of the neutron-derived porosities. The tomograms provide information on the subsurface sedimentary architecture and an estimate of the subsurface porosity.

\section{Acknowledgments}

Inland Northwest Research Alliance grant BSU002 and U.S. Army Research Office grant DAAH04-96-1-0318 supported this project. Cooperative arrangements with the Idaho Transportation Department, the U.S. Bureau of Reclamation, and Ada County allow development and use of the BHRS and we gratefully acknowledge them. Michael Knoll helped with earlier phases of this work.

\section{References}

Aldridge, D.F., and Oldenburg, D.W., 1993, Two-dimensional tomographic inversion with finite-difference traveltimes: Journal of Seismic Exploration, 2, 257-274.

Alumbaugh, D., Chang, P.Y., Paprocki, L., Brainard, J.R., Glass, R.J., and Rautman, C.Z., 2002, Estimating moisture contents in the vadose zone using crossborehole ground penetrating radar: A study of accuracy and repeatability: Water Resources Research, 38, 1309, doi:10.1029/2001/WR000754.

Barrash, W., and Clemo, T., 2002, Hierarchical geostatistics and multifacies systems: Boise Hydrogeophysical Research Site, Boise, Idaho: Water Resources Research, 38, 1196, doi:10.1029/2002/WR001436.

Barrash, W., and Reboulet, E.C., 2004, Significance of porosity for stratigraphy and textural composition in subsurface coarse fluvial deposits, Boise Hydrogeophysical Research Site: Geological Society of America Bulletin, 116, 1059, doi:10.1130/B25370.1.

Beres, M., and Haeni, F.P., 1991, Application of groundpenetrating-radar methods in hydrogeologic studies: Ground Water, 29, 375-386.

Beres, M., Huggenberger, P., Green, A.G., and Horstmeyer, H., 1999, Using two-and three-dimensional georadar methods to characterize glaciofluvial architecture: Sedimentary Geology, 129, 1-24.

Berryman, J.G., 2000, Analysis of approximate inverses in tomography II. Iterative inverses: Optimization and Engineering, 1, 437-473.

Binley, A., Winship, P., Middleton, R., Pokar, M., and West, J., 2001, High-resolution characterization of vadose zone dynamics using cross-borehole radar: Water Resources Research, 37, 2639-2652. 
Journal of Environmental and Engineering Geophysics

Cerveny, V., and Soares, J.E.P., 1992, Fresnel volume ray tracing: Geophysics, 57, 902-915.

Chen, J., Hubbard, S., and Rubin, Y., 2001, Estimating the hydraulic conductivity at the South Oyster Site from geophysical tomographic data using Bayesian techniques based on the normal linear regression model: Water Resource Research, 37, 1603-1613.

Clement, W.P., Knoll, M.D., Liberty, L.M., Donaldson, P.R., Michaels, P., Barrash, W., and Pelton, J.R., 1999, Geophysical surveys across the Boise Hydrogeophysical Research Site to determine geophysical parameters of a shallow, alluvial aquifer: Proc. Symp. App. Geophys. Eng. Envirn. Prob. 99, 399-408.

Clement, W.P., Liberty, L.M., and Barrash, W., 2001, Using cross-hole GPR reflections to improve tomographic imaging and hydrogeologic interpretation (abs.) Geological Society of America Annual Meeting, November 1-10, 2001, Boston, MA, Abstracts with Programs, v. 33 , no. 6 , p. A-45.

Galagedara, L.W., Parkin, G.W., Redman, J.D., and Endres, A.L., 2003, Assessment of soil moisture content measured by borehole GPR and TDR under transient irrigation and drainage: Journal of Environmental and Engineering Geophysics, 8, 77-86.

Gueguen, Y., and Palciauskas, V., 1994. Introduction to the Physics of Rocks: Princeton University Press, Princeton, N. J.

Huggenberger, P., 1993, Radar facies: Recognition of facies patterns and heterogeneities within Pleistocene Rhine gravels, NE Switzerland, in Best, J.L., and Bristow, C.S. (eds.), Braided rivers: Geol. Soc. London Special Publication, 75, 163-176.
Keys, W.S., 1990. Techniques of Water-Resources Investigations of the United States Geological Survey, US Geological Survey.

Knight, R., 2001, Ground penetrating radar for environmental applications: Ann. Rev. Earth Planet. Sci., 29, 229-255.

Liberty, L.M., Clement, W.P., and Knoll, M.D., 2000, Crosswell seismic reflection imaging of a shallow cobble-and-sand aquifer: An example from the Boise Hydrogeophysical Research Site: Proceedings of SAGEEP2000, The Symposium on the Application of Geophysics to Engineering and Environmental Problems, February 20-24, 2000, Arlington, VA, p. 545-552.

Menke, W., 1989. Geophysical Data Analysis: Discrete Inverse Theory, Academic Press, Inc., San Diego.

Nolet, G., Montelli, R., and Virieux, J., 1999, Explicit, approximate expressions for the resolution and a posteriori covariance of massive tomographic systems: Geophysical Journal International, 138, 36-44.

Paige, C., and Saunders, M., 1982, LSQR: An algorithm for sparse linear equations and sparse least squares: Assn. Comp. Math. Transactions on Mathematical Software, 8, 43-71.

Tronicke, J., Dietrich, P., Wahlig, U., and Appel, E., 2002, Integrating surface georadar and cross-hole radar tomography: A validation experiment in braided stream deposits: Geophysics, 67, 1495-1504.

Vidale, J.E., 1990, Finite-difference calculation of travel times in three dimensions: Geophysics, 55, 521-526.

Wilson, L.G., Everett, L.G., and Cullen, S.J., 1995. Handbook of Vadose Zone Characterization and Monitoring: CRC Press, Boca Raton, FL. 